\title{
OS APÓSTOLOS DOS SERTÕES BRASILEIROS: UMA ANÂLISE SOBRE O MÉTODO E OS RESULTADOS DAS MISSÕES RELIGIOSAS DOS CAPUCHINHOS ITALIANOS NO SÉCULO XIX
}

The apostles of Brazilian backlands: an analysis of the method and the results of the Italian Capuchin religious missions in the XIXth century 


\title{
RESUMO
}

O método missionário utilizado pelos frades capuchinhos em território brasileiro no século XIX baseava-se em dois pressupostos principais: itinerância e pregação. Foram ouvidos por milhares de pessoas, de norte a sul do Brasil, buscando incutir culpa e mudança urgente nos comportamentos antes que o juiz do final dos tempos chegasse. A segunda vinda de Cristo era anunciada para breve, cabendo ao fiel seguir os ensinamentos dos frades para que pudessem alcançar a "salvação da alma". Este artigo tem por objetivo, portanto, analisar as práticas religiosas dos frades e o primeiro desdobramento surgido entre os povos atingidos pelas pregações. Estimuladas a praticar atos penitenciais, pessoas reuniram-se em comunidades procurando preservar o que os agentes do Evangelho haviam ensinado. Adaptando o discurso dos missionários, leigos criaram "fraternidades", prescindindo da intermediação do Estado e da Igreja, e tornando-se suspeitos para as autoridades por se organizarem fora do controle institucional.

PalaVras-CHAVE: Missão religiosa; capuchinhos italianos; século XIX; Estado; Igreja; religiosidade.

\begin{abstract}
The missionary method used by Capuchin friars in Brazil in the XIXth century was based on two main assumptions: itinerancy and preaching. They preached to thousands of people, from north to south of Brazil, trying to instill guilt and urgent change in behavior before doomsday came. The second coming of Christ was announced to happen soon, and the believers should follow the lessons of the friars in order to achieve "salvation of the soul." This article aims therefore to analyze the religious practices of the friars and the first consequences emerged among people affected by their preaching. Encouraged to practice penitential acts, people gathered in communities trying to preserve what the agents of the Gospel had taught. Adapting the speech of the missionaries, laymen created "fraternities", dispensing with the intermediation of the State and the Church, and became suspicious to the authorities for organizing themselves outside the institutional control.
\end{abstract}

KeYwORDs: religious mission; Italian capuchins; XIXth century; State; Church; religiousness.

\section{RÉSUMÉ}

La méthode missionnaire utilisée par les capucins au Brésil au XIXe siècle reposait sur deux principes de base: I'itinérance et la prédication. Ils se sont fait entendre par des milliers de personnes du nord au sud du Brésil, dans le but d'inculquer la culpabilité et le changement urgent dans le comportement avant que le juge dernier n'arrive. La seconde venue du Christ ne devrait pas tarder, et les fidèles devraient suivre les enseignements des frères pour obtenir le "salut de l'âme." Cet article vise donc à analyser les pratiques religieuses des frères et leur première conséquence parmi les personnes touchées par la prédication. Encouragés à pratiquer des actes de pénitence, les gens se sont rassemblés dans des communautés qui cherchaient à préserver ce que les agents de l'Évangile avaient enseigné. En adaptant le discours des missionnaires, des laïcs ont créé des «fraternités», indépendamment de l'intermédiation de l'État et l'Église, et sont devenus suspects aux autorités du fait de fuir du contrôle institutionnel.

Mots-CLÊS: mission religieuse; capucins italiens; XIXe siècle; État; Église; piété. 


\section{O IMPÉRIO DOS CAPUCHINHOS}

A presença de missionários religiosos a serviço do Império brasileiro foi uma constante
no território nacional por quase todo o século XIX, tendo alcançado o auge entre 1840 e 1860. 0 principal grupo de missionários a atuar no Brasil imperial foi sem dúvida o dos capuchinhos italianos, o que fez com que o período fosse chamado de "o século dos capuchinhos". ' Sua vinda esteve condicionada ao interesse do governo brasileiro em integrar o índio à vida social e econômica do país. Em linhas gerais, o governo investia em missionários estrangeiros para que atraíssem os índios às aldeias a fim de catequizá-los e inseri-los no circuito de produção econômica. Era necessário mostrar-lhes as vantagens de viver aldeados. De acordo com Kaori Kodama (2009: 244), "embora a presença de um catequista fosse considerada necessária para as aldeias, divergia-se sobre quais seriam os mais aptos para a tarefa, se párocos nacionais ou estrangeiros". ${ }^{2}$ No Segundo Reinado abriram-se as portas para os capuchinhos italianos, que, considerados os sucessores dos jesuítas na evangelização dos indígenas, vieram para o Brasil por "chamado explícito do governo" para trabalhar em missão oficial (Kodama, 2009: 125).

As atividades principais dos capuchinhos durante o período imperial eram evangelizar os índios e fazer missões populares com o objetivo maior de colaborar com o governo na pacificação dos tumultos políticos da época (Azzi, 1975b: 127). Muitos deles foram efetivamente missionários entre os índios; outros ficaram a serviço dos bispos que os enviavam às paróquias no intuito de realizar "Santas Missões"; houve ainda os que se tornaram missionários itinerantes junto às populações do interior, trabalhando inclusive como agentes do governo "especializados na neutralização de revoltas populares agrárias" (Palácios, 2012: 198). ${ }^{3}$

A ordem dos frades menores capuchinhos (O.F.M. Cap.) teve origem no século XVI, na Itália, fundada por Mateus de Bascio. Ela surgiu por iniciativa de integrantes da ordem franciscana, na verdade uma dissidência que procurou retomar a espiritualidade original de Francisco de Assis e seus primeiros companheiros quando formavam um pequeno grupo de irmãos leigos que obtiveram permissão do papa Inocêncio III para viver como eremitas, peregrinos, e mendigar seu sustento nas cidades do norte italiano do século XIII (Le Goff, 2010; Frugoni, 2011). Três séculos depois, ao buscar no ramo espiritual dos primeiros franciscanos diretrizes de comportamento, os capuchinhos deram ênfase à pobreza evangélica, à oração, à solidão e ao 
silêncio, mas conciliando essa existência com o trabalho pastoral nas comunidades (D'Alatri, 1998: 143). No século XIX, os capuchinhos se tornaram uma das ordens religiosas ligadas à Sagrada Congregação da Propaganda Fide, órgão do Vaticano especialmente voltado para o treinamento de missionários que os preparava para atuar como catequistas em diversos países do mundo, em todos os continentes. ${ }^{4}$ Inspirados no santo fundador Francisco - que alternava "ação urbana e retiro eremítico", e o "apostolado no meio dos homens com a regeneração na e pela solidão" (Le Goff, 2010: 37) - e a serviço da Santa Sé, os capuchinhos chegaram ao Brasil imbuídos de verdadeiro espírito missionário e voltados para a "reconquista das almas perdidas do Novo Mundo". Se a regra original capuchinha os orientava a consagrar a maior parte do tempo à meditação, e se somente quando "empurrados pelo espírito impetuoso deviam descer da montanha para falar ao povo" (Chatêlier, 1995: 22), no Brasil alguns frades se lançaram à estrada, tornando-se peregrinos missionários em busca das "almas perdidas".

Da parte do governo brasileiro, havia a preocupação de identificar se entre os religiosos havia algum com ideias políticas divergentes das instituições do Império - unitário, monárquico e calcado na escravidã $0^{5}$-, pois era de conhecimento das autoridades que o número de refugiados italianos vinha crescendo em função das guerras na península. Era fundamental, então, investigar se por baixo da batina não se escondiam homens com intentos "revolucionários" orientados pela ideia de República. Muitos capuchinhos eram originários do Piemonte, Reino da Sardenha, berço dos principais líderes que vinham tentando unificar a Itália à custa de guerras contra Roma. ${ }^{6}$ A averiguação dos frades recém-chegados era para evitar a entrada de religiosos republicanos, certamente o temor maior de um país monárquico que, além de estar cercado de pequenas repúblicas, pouco tempo antes havia enfrentado, em seu próprio território, uma sedição republicana. ${ }^{7}$

\section{O MÉTODO APOSTÓLICO DOS CAPUCHINHOS}

U ma das formas encontradas pelos capuchinhos para reavivar a fé nas pessoas e guiá-las na "sã moral" era exortá-las a participar de obras como a ereção de cruzeiros, a reforma ou construção de cemitérios, capelas e igrejas. Incentivar e estar à frente dessas operações fazia parte do método dos frades italianos, tendo sido essas verdadeiras marcas de sua presença no Brasil o que orientou, não muitos anos depois, as ações de missionários como o padre Ibiapina e beatos como Antônio Conselheiro. ${ }^{8}$ Encontrando receptividade nas autoridades locais, os religiosos passavam então a animar o povo com "palavras ardentes e rudes", eloquência "arrebatadora e feroz queimando como brasa", algo que, segundo Câmara Cascudo, era típico dos capuchinhos (apud Azzi, 2001: 48). Vistos como homens "de ver- 
dadeira fé, inteligência, sincera adesão à glória de Nosso Senhor, de moralidade e exemplo de santidade", ${ }^{9}$ os religiosos exerciam um apelo junto às pessoas que surtia efeito imediato. Em pouco tempo, onde nada havia ou o que existia estava em ruínas, erguiam-se igrejas, capelas, muros de cemitérios ou cruzeiros que se tornavam objeto de veneração. Por essa capacidade de mobilização e ordenação social, os capuchinhos foram recebidos com grande simpatia pelas lideranças das vilas. Muitas vezes as autoridades locais pediam aos bispos que os frades se tornassem vigários das vilas.

Os artifícios utilizados pelos capuchinhos para reavivar a fé ou conclamar o povo a auxiliar em obras eram geralmente bem aceitos pelas autoridades locais. Contudo, havia quem desconfiasse da metodologia empregada por eles, como o pároco da freguesia de Rio Claro, José Antônio da Silva Chaves, que também era secretário da diocese fluminense. Esse padre fez duras críticas aos capuchinhos. Em carta de 18 de outubro de 1846 ao bispo fluminense dom Manoel do Monte, o padre Chaves declarou que eles estavam em missão religiosa no interior da província do Rio de Janeiro, "onde têm feito grande colheita de dinheiro por todos os meios os mais vis". Segundo ele, os frades "agora andam com uma tropa de bestas carregadas, pregando contra a escravatura no Brasil e dizendo que os pretos estão forros, como pregaram aqui em Rio Claro. Ao mesmo tempo, pedem e têm chamado escravos para os servirem". O padre até poderia simpatizar com essa posição dos missionários que se mostravam contrários à escravidão, porém não os perdoava por quererem firmar seu crédito sobre 0 descrédito do clero nacional, "inculcando virtudes próprias e insinuando ao povo rude que a Missa e os demais Sacramentos nenhum valor têm [se] celebrados por Ministros em pecado mortal". ${ }^{10}$

De acordo com Marta Amoroso (2006: 224), os capuchinhos italianos condenavam qualquer forma de trabalho escravo, mensagem que a missão veiculava na Europa como forma de defender a autonomia do projeto missionário em relação à política do governo imperial brasileiro. Nas publicações divulgadas em países europeus, os frades registravam seu desconforto com a oficialidade do regime escravocrata que imperava no Brasil (Amoroso, 2006: 513). Essa indisposição de missionários para com a escravidão na verdade já existia entre jesuítas como Antônio Vieira, que chegou a ser expulso do Brasil em 1661 por pregar um mundo para os indígenas livre do mundo colonial (Serafim Leite apud Hoornaert, 2008: 90).

Sentindo-se ofendido pelos discursos, o padre Chaves saiu em defesa do grupo dos párocos contra-atacando os frades com o recurso em que estes eram mestres: a pregação. Dirigiu-se ao povo argumentando que "o valor dos Sacramentos não dependia das virtudes ou merecimentos dos Sacerdotes, que estes não eram senão instrumentos de que Deus se servia para fazê-los e ministrá-los". Suas prédicas, contudo, não surtiram efeito, pois os fiéis não 
mais participavam das missas e vinham se negando a batizar os filhos na igreja, preferindo antes fazê-lo com os capuchinhos. 0 padre afirmou que não estranhava esse procedimento, pois sabia que o povo gostava de novidades e, por isso, deixou-se envolver pelas "Missões e [pelo] aspecto das barbas grandes dos Missionários", correndo ao encontro deles e os chamando de "Padres Santos". O fascínio que a população sentia por aqueles "apóstolos do Evangelho" minava o poder do pároco, por isso as queixas.

Ao vislumbrar religiosos como os italianos, o povo rendeu-Ihes veneração por associá-los aos profetas bíblicos, principalmente pelas barbas longas - "símbolo profético e sinal da renúncia a toda vaidade" -, mas também pela coragem de enfrentar as asperezas do sertão vestindo sandálias e hábito rústico, levando existência de total despojamento e desconforto (Azzi, 2001: 48). A vida apostólica e a perfeição evangélica transformaram os capuchinhos em legítimos seguidores de Cristo. Vistos muitas vezes em oposição aos párocos, os frades se transmutaram em "santos" capazes de atender aos anseios e expectativas da população, que, entusiasmada com essa angélica presença, abandonava seus afazeres para segui-los com o objetivo de aprender maneiras de levar uma vida santa e salvar a alma. Prolongando o tempo ao lado dos missionários, os devotos poderiam, ainda, testemunhar a realização de milagres, pois acreditavam que a santidade poderia se manifestar nesses autênticos representantes de Deus.

Conforme o padre José Antônio da Silva Chaves, os capuchinhos perceberam a influência que exerciam sobre as pessoas e aproveitaram-na em seu próprio interesse; tão logo conseguiam o que queriam, porém, davam fim às suas pregações e iam embora, deixando 0 povo "em maiores erros, crimes e ignorância". Tentando conter o "fanatismo religioso", o padre diz ter rebatido algumas expressões mal ditas pelos capuchinhos - como "os pretos estão forros" - e procurado instruir o povo para que não tomasse as palavras dos frades em seu sentido literal. Talvez tenha esclarecido aos negros que as promessas feitas pelos missionários se referiam à liberdade da alma e não se ligavam à condição do cativeiro. Seja como for, o sacerdote estava contrariado e concluiu: "não posso esperar que homens com semelhante espírito tenham cá vindo para fazer bem algum ao povo, [pois] só procuram o seu interesse para voltarem com o que pilham do nosso País". Após este desabafo, pedia desculpas ao bispo fluminense por estar usando "destas expressões e ser um pouco franco no meu juízo", mas tudo o que afirmava vinha de seu testemunho e do que ouvira de "pessoas instruídas e muito religiosas" igualmente desconfiadas das intenções dos capuchinhos e preocupadas com 0 resultado de suas missões entre o povo. ${ }^{11}$

As "Santas Missões", segundo Cândido da Costa e Silva (1982: 37), possuíam forte apelo dramático, gerando emoções, decisões intempestivas e comportamentos imprevisíveis. 0 anúncio de que frades se aproximavam para dar início à missão era "uma boa nova que corre 
célere de boca em boca por léguas em torno". A missão durava, em média, de cinco a dez dias, e sua dinâmica envolvia a todos pelas atividades propostas pelos religiosos. Ainda de madrugada, o missionário despertava o povo circulando pelas ruas entoando benditos - orações de benção - a caminho da igreja. Uma vez reunidos no templo, fazia-se a prática, também chamada de catecismo ou instrução, onde se falava sobre os sacramentos; na celebração da missa o povo cantava ofícios a Nossa Senhora. Findo o ritual, e para preencher o tempo restante, realizavam-se atividades distintas, como o atendimento às mulheres em confissão, batismos, crismas, casamentos e catequese das crianças. No turno da tarde havia cursos para os homens e, a seguir, a principal pregação do dia, em que os missionários proferiam discursos sobre os mandamentos e sobre os "Novíssimos do Homem" (Silva, 1982: 39-40). Nesse instante, os frades utilizavam recursos variados para chamar a atenção, ameaçando, inclusive, lançar o crucifixo no chão fazendo menção de pisá-lo. E entre brados de arrependimento e choros dos espectadores, os capuchinhos davam fim à pregação naquele dia. Durante as primeiras horas da noite recebiam os homens para a confissão e para a crisma.

As pessoas se viam absorvidas pela missão que se iniciava no romper do dia e entrava, muitas vezes, noite adentro. Envolvidas pelos atos religiosos, eram também exortadas a prestar serviços úteis à comunidade, como limpeza de estradas, abertura de cacimbas d'água, reforma de cemitérios e capelas e construção de cruzeiros. Todas essas tarefas eram realizadas com "motivação penitencial, expiatória, sendo o trabalho visualizado como pena, exercício de virtude" para afastar o ócio, o principal "inimigo da alma" (Silva, 1982: 40). 0 esforço e o suor eram oferecidos a Deus para abater na conta dos pecados. Os missionários procuravam deixar em atividade a numerosa população para assim evitar desordens que naturalmente surgiam em tão grandes aglomerações.

Em relação à temática das missões, predominavam os quatro pontos dos "Novíssimos do Homem" : a morte, o juízo, o inferno e o paraíso - "morte certa, hora incerta; inferno ou céu para sempre; juízo rigoroso" ${ }^{12}$ Em torno disso os missionários assentavam suas pregações, fazendo "convite à conversão provada na penitência" com o fim de dar ao povo a oportunidade de alcançar a salvação da alma. Fiéis seguidores dos frades mendicantes medievais, maximamente do ramo espiritual dos franciscanos, os capuchinhos italianos do século XIX "ergueram suas vozes como intérpretes do caos, do incompreensível", lançando as palavras em nome de Deus e procurando "dissolver as contradições da vida, através da eloquência a um só tempo agressiva, chã e patética. Visavam despertar a sensibilidade dos ouvintes e apontar a podridão do túmulo, a angústia do juízo e a possibilidade do inferno" (Silva, 1982: 42). Com discursos dessa natureza, entende-se assim a atitude das pessoas que lançavam ao fogo pertences 
vistos como sinal evidente do pecado, pois ligados ao luxo, à ostentação e à vaidade. Temiam o momento de enfrentar o juízo final e ser condenadas às chamas do inferno.

0 apostolado dos frades tinha por característica o modelo itinerante de missão, ou seja, como missionários peregrinos os frades pregavam durante certo tempo e depois iam embora, "não olhando para trás" (Fragoso, 2008: 231). 0 método era visto como adequado para atingir o maior número de pessoas, que geralmente se encontravam espalhadas pelos sertões ${ }^{13}$ e não tinham o hábito de participar de celebrações religiosas. Porém, finda a ação missionária e com os frades seguindo adiante, os devotos, de tal modo excitados pela pregação dos religiosos, lançavam-se a práticas que amalgamavam elementos de sua própria cultura com o que haviam interpretado dos ensinamentos dos religiosos. 0 resultado dessa "adaptação criativa" foi o surgimento de movimentos populares espontâneos de vivência do sagrado, formas originais de religiosidade que geralmente causavam preocupações aos párocos e às autoridades pela autonomia desenvolvida (Hoornaert, 2008: 80). Como afirmou o padre Chaves, após a passagem dos capuchinhos pela freguesia de Rio Claro o povo ficou "em maiores erros, crimes e ignorância", restando a ele tentar orientar e refrear as primeiras manifestações religiosas surgidas entre os fiéis.

\section{A “SOCIEDADE DOS PENITENTES"}

s pregações dos missionários repercutiram de modo distinto entre os espectadores, ha-
vendo quem reagisse se lançando aos rigores da vida penitencial imitando o estilo dos frades. Geralmente longe da ingerência do clero e agregando elementos da cultura popular à religião, indivíduos se tornaram uma ameaça à segurança pública e privada, como ocorreu no interior cearense em 1845, ${ }^{14}$ depois da passagem de um capuchinho. Procurando viver segundo os preceitos aprendidos com o missionário, um grupo de homens criou a "sociedade dos penitentes e defensores da Cruz" e passou a peregrinar pelo interior da província. 0 caso ganhou repercussão e exigiu das autoridades locais e depois provinciais medidas enérgicas para interromper a ação daquela "confraria" que estava coagindo os moradores a aderir à sua "seita" sob o argumento de que os pecadores, caso não se convertessem, teriam sua almas consumidas pelo fogo do inferno.

Por ser inusitado, o episódio mereceu constar no relatório de 1846 do ministro da Justiça José Joaquim Fernandes Torres: na "comarca do Crato, na província do Ceará, apareceram reunidos em sociedade indivíduos denominando-se penitentes, ou defensores da Cruz, que, mal compreendendo o verdadeiro sentido da palavra Divina, anunciada pelo Frei Caetano [de Messina], entenderam que a religião católica impõe a obrigação de orar continuamente e de 
praticar a mais austera penitência". Apresentaram-se armados e em grande número, cercando as casas de particulares e "obrigando os moradores a sustentá-los e a observar os seus preceitos religiosos", sendo necessário, então, "dissolver tal sociedade, o que facilmente se conseguiu mediante os esforços de alguns homens cordatos e as frequentes prédicas dos párocos das respectivas freguesias". ${ }^{15}$ Nessas situações, quando a ordem pública estava ameaçada, exigia-se o trabalho conjunto dos poderes civis e eclesiásticos, ${ }^{16} \operatorname{com}_{\text {os }}$ primeiros utilizando a força das armas e os segundos orientando pela ação das palavras. De norte a sul do Brasil, a partir da década de 1840 foram vários os casos de grupos se reunindo tentando reproduzir o que os missionários haviam ensinado. Um dos casos mais célebres ocorreu no Rio Grande do Sul em 1848, e envolveu um eremita italiano chamado João Maria de Agostini, que reuniu em torno de si milhares de fiéis que acreditavam ser ele um enviado de Deus na terra (Karsburg, 2012; 2014). Esse italiano daria origem ao santo popular denominado "Monge João Maria", cultuado até os dias de hoje nos três estados do sul do Brasil e também em São Paulo, principalmente na região de Sorocaba.

Entre os milhares de católicos atingidos pelas "pregações de choque" dos religiosos, "nas quais ameaça e superculpabilização ocupavam um lugar preponderante" (Delumeau, 2003: 302), ${ }^{17}$ a natureza do despertar religioso nem sempre resultava em algo benéfico à sociedade, ao Estado e à Igreja. Em países europeus do início do século XIX, os frades tentavam contrabalançar os sermões, ora apresentando-os com "doçura", ora com "severidade". No Brasil a prática era ao contrário, pois, devido à leitura que fizeram da moral do povo - que só pode ter saído do "inferno", segundo declarou frei Gregório de Bene ${ }^{18}$ - a iminência do juízo final foi a tática deliberada para suscitar nas consciências o sentimento do pecado, podendo este ser expiado pela penitência e a oração. Apesar do teor "apavorante" das pregações, ou por causa disso, os missionários deixaram impressões positivas por onde passavam, provocando o despertar religioso nas populações que os veneravam como "homens santos".

Devido à característica da religiosidade brasileira, que prescindia do clero para a vivência do sagrado, a atitude dos indivíduos que fundaram a "sociedade dos penitentes e defensores da Cruz" nos sertões cearenses em 1845 é bom exemplo para demonstrar os limites das "santas missões" operadas pelos capuchinhos italianos. Em casos como esse, os fiéis ultrapassaram o que Ihes fora informado, causando preocupação às autoridades pelo comportamento autônomo e agressivo. Uma vez encerrada a ação missionária, o povo aceitava as tradições ensinadas pelos pregadores, agregando-as à sua experiência empírica do sagrado, criando assim uma forma original de vivência do Evangelho. Imitando os frades, acreditavam poder alcançar a perfeição moral e, consequentemente, a salvação da alma. 


\section{CONSIDERAÇÕES FINAIS}

as duas últimas décadas, o campo historiográfico avançou a respeito das interpreta-
ções sobre o período e sobre as práticas missionárias dos capuchinhos. Partindo dos registros dos próprios frades e de estudos de caso como o utilizado neste artigo, foi possível reavaliar posições universalistas que a historiografia moderna construiu sobre o método franciscano (e capuchinho) de missão. As dimensões discursiva e pragmática foram incorporadas à análise visando uma aproximação das categorias missionárias, o que verdadeiramente consolidou certos aspectos da nova geração de estudos, como por exemplo a absoluta submissão dos capuchinhos como funcionários assalariados aos programas oficiais e a ausência de projetos autônomos das missões dos frades italianos, o que levou muitas vezes seus protagonistas a atuar de forma bastante controversa. ${ }^{19}$

Os missionários continuaram a agir nos quatro cantos do Brasil durante o restante do século XIX, o que fez surgirem outras sociedades autônomas e inúmeros indivíduos que procuraram seguir o estilo de vida e a aparência destes "santos peregrinos", configurando-se, então, movimentos perigosos para a ordem social e religiosa pretendidas. Talvez os frades não tivessem planejado prestar esse desserviço às autoridades brasileiras, mas um dado é certo: eles não aceitavam estar sujeitos às ordens do poder secular, o que ocasionou não poucos conflitos entre eles e os representantes do Estado Imperial. Esse comportamento controverso e arredio dos missionários era perigoso para as pretensões do Estado que visava criar súditos fiéis. No entanto, naquele momento (meados do século XIX), poucos perceberam o que a médio e longo prazo se confirmaria: os frades italianos, acreditando prestar serviço a Deus colocando a salvação ao alcance das pessoas comuns, foram uma das matrizes das diversas manifestações religiosas populares consideradas heterodoxas que o Brasil conheceu nos séculos XIX e XX. A "sociedade dos penitentes" no Ceará, em 1845, foi o primeiro indício de um comportamento que ganharia espaço no interior brasileiro nas décadas seguintes, de que o Arraial de Canudos (1893-1897), no interior da Bahia, e as "cidades santas" durante o Movimento do Contestado (1912-1916), no planalto catarinense, são nossos exemplos mais conhecidos.

\section{Notas}

1 Embora usassem longas barbas, os capuchinhos italianos não devem ser confundidos com os missionários franceses ou os capuchos portugueses, ambos chamados de "barbadinhos". Trata-se de um equívoco apontado pela literatura especializada, como já expôs o historiador franciscano Francisco Leite de Faria (1954, 1982).

2 Para detalhes desta divergência entre os políticos da época do Império, ver Kodama (2009: 243-260). 
3 As Santas Missões e o programa de "Catequese e Civilização" do Império seguiram uma cartografia bastante objetiva, que incidiu sobre as aldeias e a territorialidade indígenas, identificadas no período como uma das fronteiras a serem conquistadas pelo Império (Carneiro da Cunha, 1992; Amoroso, 2014). Por outro lado, os frades também atuaram em territórios marcados por movimentos sociais, mas, segundo Palácios (2012), sem muito sucesso.

4 A Propaganda Fide era uma tentativa da Santa Sé de desfazer o domínio absoluto que o padroado exercia sobre as missões em países como o Brasil, instruindo os missionários a agir em obediência e fidelidade aos interesses de Roma. Acreditando na supremacia da religião sobre a política, os capuchinhos podem ser considerados, de certo modo, ultramontanos. Segundo Guilherme Pereira das Neves (2009: 415), a postura "dita ultramontana" se traduzia numa série de medidas ou de atos que buscavam reafirmar, no fundo, o primado da religião sobre a política. Por isso os capuchinhos podem ser considerados ultramontanos, não somente porque defendiam o primado político da Santa Sé sobre as nascentes nações, mas porque acreditavam que era a religião que levava a Deus e à salvação da alma.

50 Estado Imperial brasileiro foi construído e consolidado com base no centralismo, no monarquismo e no escravismo, segundo se pode aferir a partir dos estudos de Mattos (1990), Carvalho (1996) e Ferreira (2006).

6 De acordo com uma lista de seis frades italianos que chegaram ao Brasil em 30 de novembro de 1847, a metade era do Piemonte (Arquivo Nacional - AN, Série Justiça, IJ1-998, 1846-1852).

7 Refiro-me à Revolução Farroupilha (1835-1845) no Rio Grande do Sul.

8 É o que se pode intuir a partir das fontes que apresentarei adiante e de estudos como os de Della Cava (1976), Souza (2007) e Carvalho (2008).

9 Declaração dos vereadores da vila de Itapemirim a respeito do frei Paulo Antônio de Casas-Novas, no abaixo-assinado de 9 de julho de 1845 enviado ao bispo diocesano (Arquivo da Cúria Metropolitana do Rio de Janeiro - ACMRJ, C0-35, Correspondências Diversas, 1845-55).

10 Documento do cônego José Antônio da Silva Chaves, secretário do bispado e pároco da freguesia de Rio Claro, ao bispo dom Manoel do Monte, 18 de outubro de 1846 (ACMRJ, CO-23 - 1826 a 1889).

11 A forte reação do padre Chaves vincula-se ao contexto de contra-ataque do clero secular, nacionalista e de "tendência regalista", segundo Riolando Azzi (1975: 137), à presença cada vez mais constante dos religiosos estrangeiros no Brasil daquela época. Assim como ele, padres de São Paulo também escreviam a respeito dos privilégios concedidos aos frades, mostrando todo o seu descontentamento com a situação.

12 Compêndio da Doutrina Cristã criado no Concílio de Trento no século XVI e ainda utilizado pelos padres missionários no século XIX (Silva, 1982: 41). No Brasil, foi inserido em 1707 nas Constituições Primeiras do Arcebispado da Bahia para servir de guia aos pregadores de então.

13 Utilizo o termo sertão tal como o entendiam as autoridades, os viajantes e os missionários do século XIX, ou seja, como sinônimo de território pouco habitado, desconhecido, geralmente hostil pela presença de indígenas, de geografia que variava entre florestas, matas ou desertos. Contudo, o termo é mais complexo que isso, pois ocupou lugar de destaque no imaginário popular entre os séculos XVI e XVIII e na literatura brasileira desde o século XIX. Entendido ora como fronteira, temerária e alvissareira, ora como local de sacrifício dos desbravadores destemidos, foi um lugar "mítico, ignoto e hostil" (Malheiros, 2008: 69). Sobre as diferentes significações do termo, consultar Amado (1995), Mader (1995) e Lima (1999).

14 Sobre a "sociedade dos penitentes", o governo da província do Ceará fez um primeiro comunicado ao ministro da Justiça em junho de 1845. Em 17 de julho, afirmou que o chefe de polícia fora até a região dos fatos 
para perseguir com rigor os criminosos. Prometeu o presidente da província que em breve enviaria relatório circunstanciado, acrescentando: "não pouparei meios para conservar esta província em perfeita paz" (Ofício do presidente da província do Ceará, Ignácio Corrêa de Vasconcelos, ao ministro da Justiça, 17 de julho de 1845. AN, Série Justiça, IJ1-262).

15 Biblioteca Nacional - BN, Setor de Periódicos, Relatório do ministério da Justiça - RMJ, 1846, p. 16.

16 Em 17 de outubro de 1845, o ministro da Justiça comunicou ao bispo de Pernambuco, Antônio Paulino Limpo de Alves, os "excelentes serviços prestados pelos párocos da província do Ceará contra o fanatismo da dita Sociedade dos Penitentes" (AN, Série Justiça, ${ }^{*} J 1-8^{*}$ f. 31).

17 Jean Delumeau cita estudos sobre a ação dos missionários na Europa da Restauração, de 1815 a 1830, confirmando que as pregações eram voltadas mais para o "temor do que para o amor" (2003: 302-307).

18 Declaração feita pelo frade em carta destinada ao bispo dom Manoel do Monte em 1 de maio de 1845 (ACMRJ, CO 02, Correspondências Recebidas (1825-1910), Primeiro Maço 1829-1894).

19 Entre as pesquisas que contribuíram para essa "guinada" com relação às análises que partiram das inscrições e performances capuchinhas relativas às santas missões e ao programa de catequese e civilização dos índios, destacam-se as de Carneiro da Cunha (1992), Daher (2002), Amoroso (1998 e 2014), Santos (2012) e Palacios (2012).

\section{REFERÊNCIAS BIBLIOGRÁFICAS}

AMADO, Janaína. Região, sertão, nação. Estudos Históricos, Rio de Janeiro, vol. 8, n. 15, 1995, p. 145-151. Disponível em: http://www.cpdoc.fgv.br/revista/arq/169.pdf.

AMOROSO, Marta Rosa. Mudança de hábito: catequese e educação para índios nos aldeamentos capuchinhos. Revista Brasileira de Ciências Sociais, São Paulo, vol. 13, n. 37, jun. 1998. Disponível em: <http://www. scielo.br/scielo.php?script=sci_arttext\&pid=S0102-69091998000200006\&lng=en\&nrm=iso $>$. Acesso em 25 mar. 2011.

Catequese e evasão: etnografia do aldeamento indígena São Pedro de Alcântara, Paraná (18551895). Tese de doutorado em Antropologia, Universidade de São Paulo, 1998b.

A primeira missa: memória e xamanismo na Missão Capuchinha de Bacabal (Rio Tapajós 1872-82). In: MONTERO, Paula (org.). Deus na aldeia: missionários, índios e mediação cultural. São Paulo: Globo, 2006, p. 209-233.

Terra de índio. Imagens em aldeamentos do Império. São Paulo: Terceiro Nome, 2014, vol. 1.

AZZI, Riolando. Os Capuchinhos e o movimento brasileiro de reforma católica do século XIX. Revista Eclesiástica Brasileira, vol. 35, fasc. 137, mar. 1975, p. 123-139.

A Sé primacial de Salvador. Período imperial e republicano, vol. II. Salvador/ Petrópolis: UCSAL/ Editora Vozes, 2001.

CARNEIRO DA CUNHA, Manuela (org.). Política indigenista no século XIX. In: História dos índios no Brasil. 2a ed. São Paulo: Companhia das Letras/ Secretaria Municipal de Cultura/ FAPESP, 1992, p. 133-154.

CARVALHO, Ernando Luiz G. de. A missão Ibiapina. Passo Fundo: Gráfica Editora Berthier, 2008. 
CARVALHO, José Murilo de. A construção da ordem: a elite política imperial; Teatro das Sombras: a política imperial. $2^{\mathrm{a}}$ ed. Rio de Janeiro: Editora UFRJ/ Relume-Dumará, 1996.

CHÂTELIER, Louis. A Religião dos pobres: as missões rurais na Europa e a formação do catolicismo moderno. Séc. XVI - XIX. Lisboa: Editorial Estampa, 1995.

D’ALATRI, Mariano. Os capuchinhos das Marcas - Uma história franciscana. Porto Alegre: EST Edições, 1998.

DAHER, Andrea. Les singularités de la France equinoxiale. Histoire de la mission des pères capucins au Maragnan (1612-1615). Paris: Honoré Champion, 2002, vol. 1.

DELLA CAVA, Ralph. Milagre em Joaseiro. Trad. Maria Yedda Linhares. Rio de Janeiro: Paz e Terra, 1976.

DELUMEAU, Jean. O pecado e o medo: a culpabilização no Ocidente (séculos 13-18). 2 vol. Trad. Álvaro Lorencini. Bauru: EDUSC, 2003.

FARIA, Francisco Leite de. Os barbadinhos franceses e a Restauração pernambucana. Coimbra: Coimbra Editora, 1954.

Os capuchinhos em Portugal e no Ultramar português. Lisboa: Academia Portuguesa de História, 1982.

FERREIRA, Gabriela Nunes. O Rio da Prata e a consolidação do Estado Imperial. São Paulo: Hucitec, 2006.

FRAGOSO, Hugo. A Igreja na formação do Estado Liberal (1840-1875). In: BEOZZO, José Oscar (org.). História da Igreja no Brasil. Segunda época. A Igreja no Brasil no século XIX. Tomo II/2, 2a ed. Petrópolis: Paulinas I Vozes, 1985.

FRUGONI, Chiara. Vida de um homem: Francisco de Assis. Trad. Frederico Carotti. São Paulo: Companhia das Letras, 2011.

HOORNAERT, Eduardo. A evangelização do Brasil durante a primeira época colonial. In: História da Igreja no Brasil: ensaio de interpretação a partir do povo. Primeira época - Período Colonial. 5 a ed. Petrópolis: Vozes, 2008, p. 21-152.

KARSBURG, Alexandre de Oliveira. O eremita do Novo Mundo: a trajetória de um peregrino italiano pela América do século XIX. Tese de doutorado, PPGHIS, Universidade Federal do Rio de Janeiro, 2012.

. O eremita das Américas: a odisseia de um peregrino italiano no século XIX. Santa Maria: Editora da UFSM, 2014.

KODAMA, Kaori. Os índios no Império do Brasil: a etnografia do IHGB entre as décadas de 1840 e 1860. Rio de Janeiro: Fiocruz/ São Paulo: EDUSP, 2009.

LE GOFF, Jacques. São Francisco de Assis. Trad. Marcos de Castro. 9a ed. Rio de Janeiro: Record, 2010.

LIMA, Nísia Trindade. Um sertão chamado Brasil: intelectuais e representação geográfica da identidade nacional. Rio de Janeiro: Revam/IUPERJ-UCAM, 1999.

MADER, Maria Eloisa Noronha de Sá. O vazio: o sertão no imaginário da colônia nos séculos XVI e XVII. Dissertação de mestrado. PUC, Rio de Janeiro, 1995.

MALHEIROS, Márcia. Homens da fronteira: índios e capuchinhos na ocupação dos sertões do leste, do Paraíba ou Goytacazes (séculos XVIII e XIX). Tese de doutorado em História, Universidade Federal Fluminense, Niterói, 2008. 
MATTOS, IImar R. de. O tempo saquarema: a formação do Estado Imperial. 2ª ed. São Paulo: Hucitec, 1990.

NEVES, Guilherme Pereira das. A religião do Império e a Igreja. In: GRINBERG, Keila; SALLES, Ricardo (orgs.). 0 Brasil Imperial, vol. I: 1808-1831. Rio de Janeiro: Civilização Brasileira, 2009, p. 377-428.

PALACIOS, Guillermo. Política externa, tensões agrárias e práxis missionária: os capuchinhos italianos e as relações entre o Brasil e o Vaticano no início do Segundo Reinado. Revista de História, São Paulo, n. 167, jul./dez. 2012, p. 193-222.

POMPA, Cristina. Leituras do 'fanatismo religioso' no sertão brasileiro. Novos Estudos. CEBRAP, São Paulo, v. 69, 2004, p. 71-88.

SANTOS, Fabrício Lyrio. Da catequese à civilização: colonização e povos indígenas na Bahia (1750-1800). Tese de doutorado em História, Programa de Pós-Graduação em História Social da Universidade Federal da Bahia, Salvador, 2012.

SILVA, Cândido da Costa e. Roteiro da vida e da morte: um estudo do catolicismo no sertão da Bahia. São Paulo: Ática, 1982.

SOUZA, Otilia Aparecida Silva. As marcas da alma: reflexões acerca de um grupo de penitentes do Cariri cearense. Anais do / Simpósio Internacional de Ciências das Religiões, João Pessoa, 16 a 18 de julho de 2007. 